\title{
Biological Activity of Methyl tert-butyl Ether in Relation to Soil Microorganisms has a Negative Environmental Impact
}

\author{
Gholam Hosein Shahidi Bonjar \\ Departments of Plant Pathology and Biotechnology, College of Agriculture \\ Bahonar University of Kerman, Iran
}

\begin{abstract}
Fuel oxygenates are added to gasoline to enhance combustion efficiency of automobiles and reduce air pollution. Methyl tert-butyl ether (MTBE) is the most commonly used oxygenate because of its low cost, high-octane level and ease of blending with gasoline. However, due to its water solubility, high mobility and low biodegradability it leaches in soil subsurface at the speed of groundwater. Amending gasoline with MTBE has made a widespread contamination of groundwater, surface waters in coastal environments and at low levels in well water. Although current public concern about MTBE contamination is widely discussed, but its adverse effects on soil micro flora is not yet understood. Soil Streptomycetes are beneficial to soil productivity and are of the major contributors to the biological buffering of soils having antagonistic activity against wide spectrum of pathogenic bacteria and fungi. Streptomyceticidal activity of Methyl tert-butyl ether (MTBE) is being reported here. Adverse effect of MTBE against four soil-inhabitant Streptomyces spp. isolates and two plant root-pathogens was investigated. To elucidate antimicrobial activity of MTBE, it was tested against four soil isolates of Streptomyces; a plant bacterial-pathogen, Erwinia carotovora and a plant root fungal-pathogen, Fusarium solani. MTBE did not reveal any growth inhibitory-activity against $E$. carotovora and $F$. solani but showed strong inhibitory effect against Streptomyces spp. isolates. The Minimum Inhibitory Concentration (MIC) was 1/800 of the original MTBE. Fuel leaks and spills can adversely suppress or eliminate the Streptomyces role in the soil causing alteration in the balance of soil micro flora. This change will lead to domination of microorganisms with adverse biological or ecological effects. Fortunately, major oil companies have decided to phase out MTBE from automobile fuels because of its adverse effect on environment and human health.
\end{abstract}

Key words: Soil Micro Flora, Soil Contamination, MTBE, Antagonism

\section{INTRODUCTION}

Since 1992, Methyl tert-butyl ether (MTBE) has been added to gasoline worldwide in order to enhance combustion efficiency and reduce air pollution. It is the most commonly used oxygenate because of its low cost, high-octane level and ease of blending with gasoline [1]. Due to its water solubility, high mobility and low biodegradability it leaches in soil subsurface at the speed of groundwater. Amending gasoline with MTBE has made a widespread contamination of soil, groundwater and surface waters in coastal environments and at low levels in wells water [2-6]. The carcinogenic effect of MTBE has been observed in animals and furthermore, its metabolites have shown mutagenicity effects in the Ames bacterial assay [7, 8]. Although current public concern about MTBE contamination is widely discussed and is at the focus of environmental scientists, but its adverse effects on agricultural soil micro flora is not yet understood. To reduce the problem of MTBE contamination, several workers reported laboratory methods of remediation, especially bioremediation [9-13] however, these methods are not practically established for wide spread use in the natural environment. At the present study, to investigate inhibitory effect of MTBE against some microorganisms of agricultural soils, four_soilinhabitant Streptomyces sp. isolates, Erwinia carotovora a bacterial and Fusarium solani a fungal, plant root-pathogens were tested by in vitro assays. The aim of the study was to elucidate if contamination of agricultural soils with MTBE can cause adverse effects in soil environment especially on the activity of soil Streptomyces. These findings support the wide range of reports on harmful effects of MTBE in environment [14-18].

\section{MATERIALS AND METHODS}

Microorganisms: The tested micro organisms, Erwinia carotovora Jones, Fusarium solani Mart. and four Streptomyces spp. isolates were prepared from the Research Laboratory of Department of Plant Pathology, College of Agriculture, Bahonar University of Kerman, Iran. The Streptomyces isolates were isolated from soil, identified at Genus level and proved beneficial but non pathogenic. 
Table 1: Differential Antimicrobial Activity of MTBE Serial Dilutions on four Streptomyces sp. Isolates, Erwinia carotovora and Fusarium solani. The Numbers Indicate the Diameter of Inhibition Zones in $\mathrm{mm}$. The Test was an in vitro Bioassay Performed by Agar Diffusion Method

\begin{tabular}{|c|c|c|c|c|c|c|}
\hline \multirow[b]{2}{*}{ Microorganisms } & \multicolumn{6}{|c|}{ MTBE Dilutions } \\
\hline & $1: 10$ & $1: 100$ & $1: 200$ & $1: 400$ & $1: 800$ & $1: 1600$ \\
\hline Streptomyces isolate No. 18 & 30 & 28 & 22 & 16 & 14 & - \\
\hline Streptomyces isolate No. 51 & 51 & 41 & 35 & 22 & 17 & - \\
\hline Streptomyces isolate No. 59 & 44 & 39 & 30 & 18 & 15 & - \\
\hline Streptomyces isolate No. 71 & 41 & 32 & 34 & 19 & 25 & - \\
\hline Erwinia carotovora & - & - & - & - & - & - \\
\hline Fusarium solani & - & - & - & - & - & - \\
\hline
\end{tabular}

$-=$ Zero growth, no inhibitory effect

MTBE: Serial dilutions of 1:10, 1:100, 1:200, 1:400, 1:800 and 1:1600 of MTBE were prepared in dimethyl sulfoxide (DMSO): methanol (1:1, v/v) solvent (DM solvent), sealed and kept refrigerated before use.

Bioassay Methods: Erwinia carotovora, the bacterium, cultured on Mueller-Hinton-Agar medium (MHA, Merk, Germany). For assays, suspension of approximately $1.5 \times 10^{6}$ cells $\mathrm{mL}^{-1}$ in sterile normal saline were prepared as described by Forbes et al. [19] and about $1.5 \mathrm{~mL}$ of it was uniformly seeded on MHA in $9 \times 1.2 \mathrm{~cm}$ glass Petri dishes, left aside for $15 \mathrm{~min}$ and excess of suspension was then drained and discarded properly. Wells of $6 \mathrm{~mm}$ in diameter and about $2 \mathrm{~cm}$ apart were punctured in the culture media using sterile cork borers and MTBE dilutions administered to fullness in the corresponding wells.

Fusarium solani, the plant root pathogenic fungus, was cultured on Potato Dextrose Agar medium (PDA). For assays, suspension of fugal spores was uniformly seeded on PDA medium using sterile cotton swabs and assayed as mentioned.

Streptomyces isolates were cultured on Casein Glycerin Agar medium (CGA). For assays, suspensions of spores were uniformly seeded on CGA using sterile cotton swabs and assayed as above.

Culture plates were incubated at $29^{\circ} \mathrm{C}$ for $24 \mathrm{hr}$ for $E$. carotovora, 3-5 days for $F$. solani and Streptomyces isolates. Bioactivity was determined by measuring Diameter of Inhibition Zones (DIZ) in mm. DM solvent controls were included, although no antimicrobial activity noted in the solvent employed for the test. All samples were tested in triplicate and the mean values were recorded.

Mode of Action of MTBE Inhibitory Effect: To determine if mode of action of MTBE is Streptomyceticidal or Streptomycetistatic, by using transfer needles smears from MTBE inhibitory zones of all sensitive isolates were streaked to new plates of CGA medium aseptically. As controls, similar transfers were made from non-inhibitory arias of the corresponding isolates. Plates were incubated at $29^{\circ} \mathrm{C}$ for 3-5 days and then evaluated for the presence or lack of Streptomyces growth. All tests were performed in triplicates.

\section{RESULTS AND DISCUSSION}

Differential Antimicrobial Activity of MTBE: Strong inhibitory effect of MTBE was noticed against Streptomyces isolates, but no growth inhibition was observed in E. carotovora and $F$. solani, the plant pathogens. Inhibitory effects of MTBE on four Streptomyces isolates are presented in Table 1.

Minimum Inhibitory Concentration (MIC) of MTBE: Minimum Inhibitory Concentration (MIC) of MTBE was $1 / 800$ of the original MTBE against all of the tested Streptomyces isolates.

Mode of Action of MTBE: In all triplicate tests, no growth was recovered in transfers from inhibition zones, representing that apparently mode of action of MTBE is streptomyceticidal upon isolates of this study. Normal growth observed in case of controls. However, further investigation is in process for ruling out this type of physiological response.

It is well known that Streptomyces spp. are of the major contributors to the biological buffering of soils exerting antagonistic activity against wide range of soil bacteria and fungi, have roles in decomposition of organic matter conductive to crop production and are potential producers of antibiotics [20, 21]. Diminishing their role in soil can alter the balance of soil micro flora and dominate microorganisms with hazardous biological or ecological effects. E. carotovora and $F$. solani are of major plant-root pathogens which under normal conditions are partially suppressed by antagonistic activity of soil Streptomyces spp. [22, 23]. Spread of MTBE in agricultural soils occurs by spills or leakage of gasoline in the vicinity of reservoirs or gasoline pumps constructed in the fields during in and out refills. From there, by many ways as irrigation, runoffs after precipitations, field animals, soil levelers and contaminated mud on field machine-tires, MTBE 
spreads around the field. As a result, concentration of MTBE increases in soil upon time causing suppression of these beneficial microorganisms. Consequently, the increased soil contamination by MTBE can lead to reduction in soil fertility, eruption of harmful microorganisms causing detrimental changes in soil health and fertility. For better elucidation of its adverse effects and spectrum of bioactivity, further inhibitory and cytotoxic activities of MTBE should be investigated against wider range of soil-inhabitant organisms. As expressed by many researchers and public media, MTBE may be one of the greatest unfolding environmental challenges in America's history [15-18]. Eliminating it from fuel and its remediation from soil and water should receive special attentions from governmental and research agencies in the affected countries throughout the globe.

\section{ACKNOWLEDGMENT}

The result of this research is dedicated to Mrs. F. Saba and Mr. A. Afzalipour, the founders of the University at Kerman. Thanks to Research Affairs Office of Bahonar University of Kerman for support of this study.

\section{REFERENCES}

1. Johnson, R., J. Pankow, D. Bender, C. Price and J. Zogorski, 2000. MTBE, to what extent will past releases contaminate community water supply wells? Environ. Sci. Technol., 32: 210-217.

2. Hoffert, S.P., 1998. Haze of uncertainly surrounds gas additive. The Scientist, 12: 7.

3. Reuter, J.E., B.C. Allen, R.C. Richards, J.F. Pankow, C.R. Goldman, R.L. Scholl and J.S. Seyfried, 1998. Concentrations, sources and fate of the gasoline oxygenate methyle-tert-butyl ether (MTBE) in the multiple-use lake. Environ. Sci. Technol., 32: 3666-3672.

4. Brown, J.S., S.M. Bay, D.J. Greenstein and W.R. Ray, 2000. Concentrations of methyle-tert-butyl ether (MTBE) in inputs and receiving waters of Southern California. Southern California Coastal Water Research Project Authority, 1999-2000 Annual Report.

5. Bennett, G.F., 2001. MTBE: Effects on soil and groundwater resources. J. Hazard. Material, 88: 141-144.

6. An, Y., D.H. Kampbell and G.W. Sewell, 2002. Water quality at five marines in Lake Texoma as related to methyle-tert-butyl ether (MTBE). Environmental Pollution, 118: 331-336.

7. Caprino, L. and G.I. Togna, 1998. Potential health effects of gasoline and its constituents: A review of current literature (1990-1997) on toxicological data. Environmental Health Perspectives, 106: 115-125.
8. Williams-Hill, D., C.P. Spears, S. Prakash, G.A. Olah, T. Shamma, T. Moin, L.Y. Kim and C.K. Hill, 1999. Mutagenicity studies of methyle-tertbutyl ether using the Ames tester strain TA102. Mutation Res., 446: 15-21.

9. Salanitro, J., L. Diaz, M. Williams and $\mathrm{H}$. Wisniewski, 1994. Isolation of a bacterial culture that degrades methyl t-butyl ether. Appl. Environ. Microbiol., 60: 2593-2596.

10. Hardison, L., S. Curry, S. Ciuffetti and M. Hyman, 1997. Metabolism of diethyl ether and cometabolism of methyl tert-butyl ether by a filamentous fungus, a Graphium sp. Appl. Environ. Microbiol., 63: 3059-3067.

11. Hanson, J., C. Ackerman and L. Scow, 1999. Biodegradation of methyl tert-butyl ether by a bacterial pure culture. Appl. Environ. Microbiol., 65: 4788-4792.

12. Fortin, N., M. Morales, Y. Nakagawa, D. Focht and M. Deshusses, 2001. Methyl tert-butyl ether (MTBE) degradation by a microbial consortium. Environ. Microbiol., 3: 407-416.

13. Steffan, R., K. Mc Clay, S. Vainberg, C. Condee and D. Zhang, 2001. Biodegradation of gasoline oxygenates Methyl tert-butyl ether, Ethyl tert-butyl ether and Tert-amil methyl ether by propaneoxidizing bacteria. Appl. Environ. Microbiol., 63: 4216-4222.

14. Baehr, A.L. and O.S. Zapecza, 1998. Methyl tertbutyl ether (MTBE) and other volatile organic compounds in lakes in by ram township, Sussex County, New Jersey, Summer 1998; In cooperation with the Sussex County Health Department. Available on Internet at: http://nj.usgs.gov/publications /WRIR/wrir98-4264.pdf

15. Mahler, B.J., M.G. Canova and M.O. Gary, 2001. Occurrence of selected volatile organic compounds and soluble pesticides in texas public water-supply source waters, 1999-2001, Fact Sheet 020-02, In cooperation with Texas Natural Resource Conservation Commission. Available on Internet at: http://water.usgs.Gov/pubs/fs/fs-020-02/fs_020-02.htm

16. Phase Separation Science, Inc., 2004. Phase Facts, MTBE -The UST Program's Next Great Challenge. Available on Internet at: http://www.phaseonline.com/tech_updates/phasefact_02.html

17. Smith, A.E., B. Hunter and M. Loiselle, 1998. Presence of MTBE and other Gasoline Compounds in Maine's Drinking Water Supplies - A Preliminary Report. Bureau of Health, Department of Human Services; Bureau of Waste Management \& Remediation, Department of Environmental Protection and Maine Geological Survey, Department of Conservation. Available on Internet at: http://www.maine.gov/dhhs/ehu/wells/MTBE. PDF 
18. Toccalino, P., 2004, Human-Health Effects of MTBE: A Literature Summary. Available on Internet at: http://sd.water.usgs.gov/nawqa/vocns/mtbe_hh_su mmary.html

19. Forbes, B.A., D.F. Sahm, A.S. Weissfeld and E.A. Trevino, 1990. Methods for Testing Antimicrobial Effectiveness. In: Bailey \& Scott's Diagnostic Microbiology. (Eds. E.J. Baron, L.R. Peterson and S.M. Finegold), Mosby Co., St Louis, Missouri, pp: 171-194.

20. Gottleib, D., 1973. General Consideration and Implication of the Actinomycetales. In: Actinomycetales: Characteristics and Practical Importance. (Eds. G. Sykes and F.A. Skinner), Academic Press, London, pp: 1-9.
21. Okami Y. and K. Hotta, 1988. Search and Discovery of New Antibiotics. In: Actinomycetes in Biotechnology. (Eds. M. Goodfellow, S.T. Williams and M. Modarski) Academic Press, London, pp: 33-67.

22. Demain, A.L., 1998. Induction of microbial secondary metabolism. Intl. Microbiol., 1: 259264.

23. Getha, K. and S. Vikineswary, 2002. Antagonistic effects of Streptomyces violaceusniger strain G10 on Fusarium oxysporum f.sp. cubense race 4: Indirect evidence for the role of antibiosis in the antagonistic process. Indust. Microbiol. Biotechnol., 25: 303-310. 